\title{
Reframing dan Teh Herbal Rosela sebagai Terapi Antihipertensi di Klumprit, Sukoharjo
}

\author{
Noviana Dewi*, Fitria Diniah Janah Sayekti \\ Program Studi Teknologi Laboratorium Medis, Sekolah Tinggi Ilmu Kesehatan Nasional, Surakarta
}

Submisi: 15 Juni 2019 ; Revisi: 05 Maret 2020; Penerimaan: 25 Juni 2020

Kata Kuuci:
Tekanan darah
tinggi
Reframing
Terapi
The Rosella

Teywords: High blood pressure Reframing Therapy Rosella tea

\begin{abstract}
Abstrak Hipertensi merupakan penyakit tidak menular yang dapat menyebabkan kematian. Namun penyakitini belum teratasi dengan baik karena tidak menunjukkan gejala yang spesifik. Kegiatan bakti ini bertujuan untuk mengedukasi lansia tentang mengantisipasi hipertensi secara mandiri. Edukasi dilakukan secara promotif dengan memberikan penyuluhan dan diskusi tanya jawab terkait hipertensi dan bahayanya; preventif dengan pemeriksaan kesehatan yang meliputi pemeriksaan tekanan darah, gula darah dan kolesterol disertai informasi angka normal dan anjuran pentingnya pemeriksaan berkala, secara kuratif dengan mengolah kelopak bunga rosella yang telah dikeringkan sebagai teh herbal antihipertensi; secara rehabilitasi dengan membingkai ulang pelatihan terapi untuk mengurangi tingkat stres dengan mengubah pikiran negatif menjadi pikiran positif. Hasil pengolahan pre-test dan post-test menunjukkan peningkatan rata-rata dari 54,74 menjadi 84,71 yang berarti pengetahuan peserta tentang hipertensi dan pengobatannya meningkat. Hasil analisis menggunakan uji-t berpasangan menunjukkan bahwa ada perbedaan yang signifikan antara sebelum dan sesudah perlakuan.
\end{abstract}

Abstra ct Hypertension is a non-infectious disease that can cause death. However, this disease has not been resolved properly because it does not show specific symptoms. This service activity aims to educate the elderly about anticipating hypertension independently. Education is carried out promotively by providing counselling and discussion of questions and answers related to hypertension and its dangers; preventively with medical check-up which includes checking blood pressure, blood sugar and cholesterol accompanied by normal number information and recommended the importance of periodic check-ups, curatively by processing dried petals of Rosella flower as antihypertensive herbal tea; rehabilitatively with reframing therapy training to reduce stress levels by changing negative thoughts into positive thoughts. The results of the pre-test and post-test processing showed an increase in average from 54.74 to 84.71, which means that the participants' knowledge about hypertension and its treatment increased. The results of the analysis using paired sample t-test showed that there were significant differences between before and after treatment.

\section{PENDAHULUAN}

Satu dari empat orang dewasa di dunia mendenita tekanan darah tinggi. Setiap tahun, 1 dari 7 orang meninggal karena hipertensi ( 7 juta per tahun). Berdasarkan data World Health Orga nization (WHO) diketa hui bahwa dari $50 \%$ penderita hipertensi di dunia, hanya $25 \%$ yang mendapatkan pengobatan dan hanya $12,5 \%$ yang dapat ditangani dengan baik (Qowi et al., 2011). Menurut Purnomo (2009), pemantauan tekanan darah secara rutin merupakan tindakan penting untuk

ISSN 2460-9447 (print), ISSN 2541-5883 (online)

${ }^{*}$ Corresponding author : Noviana Dewi

Program Studi Teknologi Laboratorium Medis, Sekolah Tinggi IImu Kesehatan Nasional, J. Yos Sudarso, Serengan, Surakarta 57155, Jawa Tengah, Indonesia

Email: viana072@gmail.com 
mendeteksi hipertensi. Apabila tidak terdeteksi secara dini, hipertensi dapat menimbulkan komplikasi penyakit yang lebih serius, seperti stroke, serangan jantung, dan gagal ginjal sehingga biaya pengobatan selanjutnya akan lebih mahal (World Health Organiza tion, 2002).

Hasil Riset Kesehatan Dasar (Kementerian Kesehatan Republik Indonesia, 2013) menunjukkan bahwa prevalensi penyakit hipertensi di Indonesia sebesa $26,5 \%$. Provinsi Jawa Tengah a dalah salah satu provinsi yang memiliki angka kejadian hipertensi tertinggi, yaitu sekitar 26,4\%. Prevalensi hipertensi terbanyak terjadi pada la nsia, yaitu 35,6\% (usia 45-54 tahun), 45,9\% (usia 55-64 tahun), 57,6\% (usia 6574 tahun), dan 63,8\% (usia $>75$ tahun) (Kem enterian Keseha tan Republik Indonesia, 2013).

Pencegahan dan penanganan hipertensi dapat dilakukan dengan pemberian informasi dan edukasi yang benar. Hal itu diharapkan akan memberkan pengetahuan yang cukup mengenai pola hidup sehat sehingga dapat menurunkan risiko penyakit degeneratif, terutama hipertensi dan penyakit kardiovaskular (Notoatmodjo, 2003). Selama ini, masalah hipertensi pada usia lanjut merupakan permasalahan yang sukar dikendalikan karena pemahaman lansia tentang isu-isu kesehatan dan pola hidup yang benar masih rendah.

Sa lah satu upaya yang dilakukan untuk mengobati dan menurunkan angka penderita hipertensi adalah dengan pemberian obat-obatan herbal. Sa lah satu obat herbal yang digunakan a dalah kelopak kering bunga rosela (Maryani dan Kristiana, 2008). Rosela merupakan tanaman yang memiliki berbagai manfaat. Menurut Tanjong (2011), rosela dapat digunakan seba gai anti Candida yang terdapat pada plat gigi tinuan. Rosela juga berfungsi sebagaia ntibak teri (Rostinawati, 2009). Rosela dapat diolah menjadi berba gai macam olahan makanan seperti selai, sirup, puding dan teh (Widya nto dan Nelistya, 2009). Kandungan zat organik dan flavonoid yang terdapat dalam rosela dapat berperan sebagai penurun viskositas darah sehingga da pat digunakan sebagai anti hipertensi (Mardiah dkk, 2009).

Upaya lain yang dapat dilakukan untuk memperbaiki kualitas kesehatan adalah dengan tidak hanya memperbaiki kerusakan atau kelainan fisik, tetapi melibatkan kompleksitas kebutuhan, motivasi, dan prioritas individu yang dapat dilakukan melalui komunikasi interpersonal yang melibatkan jiwa, kemauan, kesadaran, dan pikiran(Aria nto, 2013). Oleh karena itu, dalam kegiatan ini juga dilakukan terapi reframing bagi penderita hipertensi sebagai upaya edukasi dan rehabilitasi, khususnya lansia pendenita hipertensi sehingga mereka lebih sehat secara psikis.
Hipertensi pada lansia juga ditemui di Desa Klumprit, Kecamatan Mojolaban, Kabupaten Sukoharjo. Di desa ini, lansia penderita hipertensi hanya mendapatkan penanganan secara parsial, yaitu hanya dari segi fisik, sedangkan penanganan secara psikis belum tersentuh. MasyarakatDesa Klumprit juga telah banyak menggunakan rosela dalam kehidupan sehari-hari. Akan tetapi, penggunaan tersebut masih bersifat empiris sehingga belum banyak yang mengetahui penjelasannya secara ilmiah. Mencermati hal tersebut, penanganan holistik bagi lansia penderita hipertensi di Desa Klumprit perlu dilakukan, yaitu dengan edukasi medical check-up, penyuluhan kesehatan, terapi reframing, serta pengolahan bunga rosella sebagai produk herbal yang dapat digunakan oleh penderita hipertensi di desa tersebut.

\section{METODE}

Kegiatan pengabdian dilakukan di Desa Klumprit, Kecamatan Mojolaban, Kabupaten Sukoharjo selama tiga bulan (mulai da ri survei sampaipengolahan hasil) dengan durasi kegia tan efektif selama dua hari (pukul $07.00-12.00$ setiap harinya). Metode yang digunakan a dalah promotif, preventif, kuratif, dan rehabilitatif. Metode pertama, yaitu promotif berupa penyuluhan kesehatan mengenai hipertensi, batasan seseorang dikatakan hipertensi, gejala-gejala awal hipertensi, dan hal-hal la in yang berkaitan dengan hipertensi. Sebelum dan setelah penyuluhan, peserta mengikuti pre-test dan post-test untuk mengetahui apakah terdapat peningkatan pemahaman perihal hipertensi pa da setiap peserta. Adapun metode yang digunakan dalam pelaksanaan penyuluhan a dalah presentasi dan diskusi tanya jawab dengan peserta.

Metode kedua, yaitu preventif berupa medical check-up gratis bagi peserta. Peserta yang bersedia melakukan medical check-up lengkap akan mendapatkan reward berupa hadiah/kado. Hal ini dilakukan untuk meningkatkan kesa daran masyarakat tentang pentingnya check-up secara rutin agar tekanan darah terkontrol sehingga komplikasi penyakit dapat dihindari.

Metode ketiga, yaitu metode kuratif benupa demonstrasi pengolahan kelopak kering bunga rosela menjadi teh yang dapat dikonsumsi sebagai altematif pengganti obat-obatan penurun tekanan darah. Dosis yang dia njurkan a dalah 2 gram kelopak bunga rosela kering yang diseduh dengan air panas $250 \mathrm{ml}$ dikonsumsi sebanyak 2 kali sehari setelah makan selama 3 minggu. Selain itu, peserta diberi bibit tanaman rosela untuk dibudidayakan dirumah masingmasing. Teknik pembudidayaan ta naman rosela juga diajarkan kepada peserta mengingat tanaman ini merupakan tanaman yang berumur pen dek, yaitu tiga bulan. 
Metode keempat, yaitu rehabilitatif berupa pelatihan teknik reframing. Reframing adalah mengubah pikiran negatif menjadi pikiran positif serta menumbuhkan rasa syukur sehingga pikiran yang menyebabkan stres dapat berkurang. Tahapan-tahapan kegia tan pengabdian kepada masyarakat ini mengikuti empat metode yang telah dijelaskan tersebut (Gambar 1).

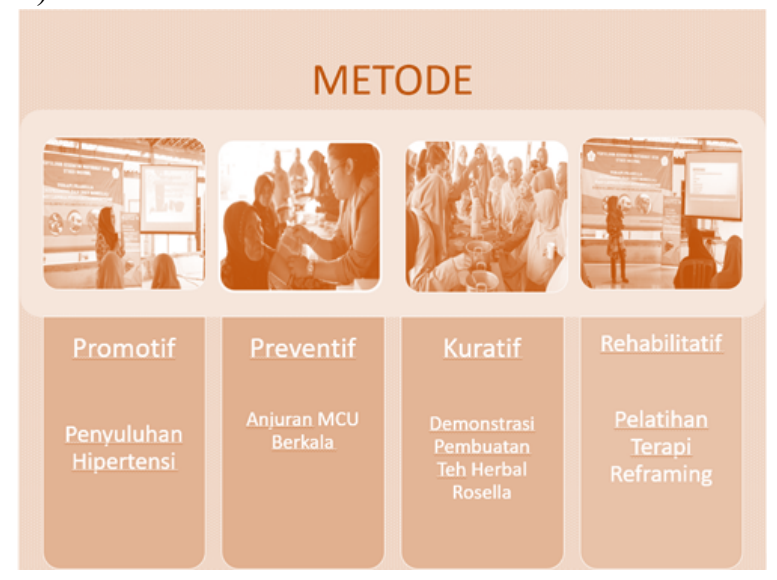

Gambar 1 Tahapan-tahapan kegiatan pengabdian kepada masyarakat

Teknik pengumpulan data dalam kegiatan ini dilakukan dengan perekaman medis berat badan, tekanan darah, ka dar gula darah, tingkat kolesterol, serta pemberian kuesioner. Adapun teknik analisis data dilakukan dengan paired sample t-test untuk mengetahui ada atau tidaknya peningkatan pengetahuan peserta dan sebagai data deskriptif untuk mengetahui persentase penderita hipertensi serta penderita hipertensi dengan komplikasi.

\section{HASILDAN PEMBAHASAN}

Berdasarkan data hasil medical check-up diketahui bahwa $80 \%$ lansia yang menjadi peserta di posyandu lansia Desa Klumprit menderita hipertensi. Persentase penderita hipertensi dapat dilihat pada Gambar 2 berikut ini.

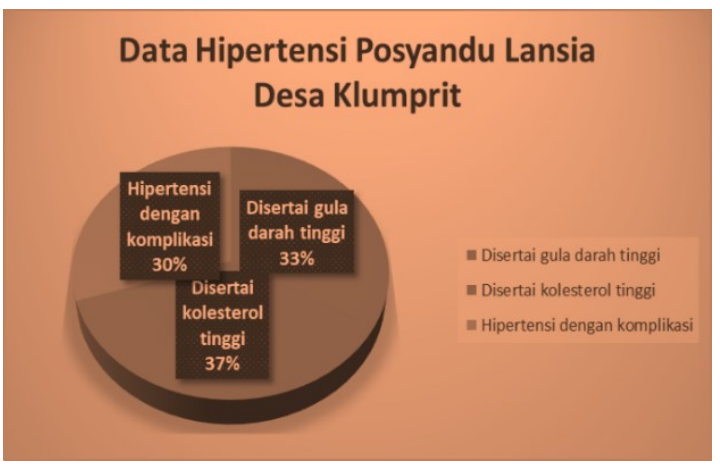

Gambar 2 Data hasil medical check-up penderita hipertensi

Berdasarkan Gambar 2 diketahui bahwa 33\% penderita hipertensi memiliki ka dar gula darah tinggi, yaitu $>140 \mathrm{mg} / \mathrm{dl}$. Sebanyak $37 \%$ penderita hipertensi memiliki kolesterol tinggi dengan angka nomal kolesterol < $220 \mathrm{mg} / \mathrm{dl}$. Sebanyak 30 pendenita hipertensi memiliki gula darah dan kolesterol tinggi a tau bisa dikatakan mengalami komplikasi hipertensi.

Berdasarkan data tersebut, edukasi kepada masyarakat untuk rajin melakukan medical check-up perlu dilakukan. Masyarakat juga perlu diberi informasi terkait bahaya hipertensi, gejala awal hipertensi, serta faktor-faktor hipertensi dan penanganannya secara mandiri, yaitu dengan terapi reframing dan konsumsi teh kelopak kering bunga rosela sesuai dosis yang dianjurkan.

Pelatihan terapi psikis berupa terapi reframing diberikan kepada peserta karena salah satu faktor hipertensi adalah stres. Terapi reframing terdiri atas beberapa tahapan, yaitu menemukan hal-hal yang menimbulkan pikiran atau yang dianggap sebagai masalah, membingkai ulang hal tersebut, mencari sisi positif dari masalah tersebut, dan apabila tidak ditemukan hal yang dapat menjadi sumber stres, maka peserta diajak untuk bersyukur dan menerima karena masih diberi masalah yang membuat hidup lebih bermakna. Hal ini merupakan salah satu cara meningkatkan psychological well-being pada lansia dengan memberikan edukasi teknik memahami kebermaknaan hidup. Indikator ketercapaian pelatihan reframing diperoleh melalui observasi yang dilakukan terhadap peserta terkait permasalahan atau pikiran nega tif yang muncul. Peserta kemudian dibantu untuk menemukan hal-hal yang dapat disyukuri dari permasalahan tersebut. Tolok ukur keberhasilan ditentukan berdasarkan hasil pengisian kuesioner pretest dan post-test serta pengukuran tekanan darah sebelum dan setelah pelatihan diberikan.

Sebelum dan setelah pelaksanaan edukasi dan pelatihan, semua peserta diminta untuk mengisi kuesioner yang terkait dengan hipertensi, reframing, dan rosela. Hasil analisis kuesioner pre-test dan posttest menunjukkan peningkatan rata-rata, yaitu dari 54,74 menjadi 84,71. Hal itu berarti bahwa pengetahuan peserta mengenai hipertensi dan penanganannya meningkat. Hasil pre-test dan post-test juga dianalisis dengan paired sample t-test. Hasil analisis menunjukkan bahwa terdapat perbedaan yang signifikan antara sebelum dan setelah diberikan perlakuan. Halitu dapat dilihatpada Gambar 3 .

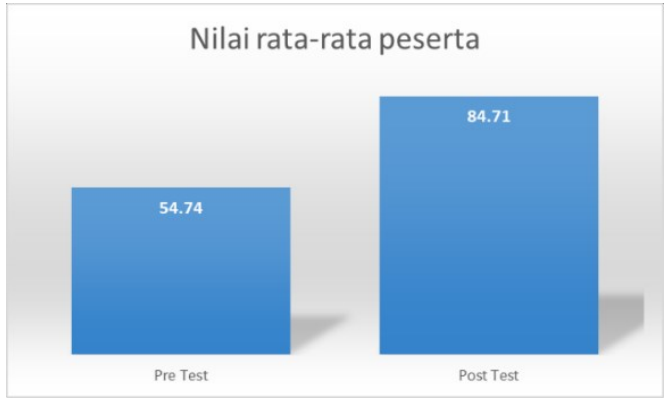

Gambar 3 Diagram peningkatan pengetahuan peserta 
Peningkatan pengetahuan ini merupakan titik awal untuk menggugah kesadaran peserta tentang bahaya hipertensi dan penanganan mandiri yang pertu dilakukan, baik secara psikis, yaitu dengan terapi reframing maupun secara fisik, yaitu dengan teh herbal rosela. Peningkatan pengetahuan dan kesadaran akan mendorong terciptanya perubahan sikap dan perilaku ke arah yang lebih positif. Perubahan tersebut diharapkan konsisten sehingga dapat menurunkan angka kematian lansia akibat hipertensi dan komplikasinya.

Hasil a nalisis kuesioner tentang kepuasan peserta terkait dengan informasi dan edukasi penanganan hipertensi menggunakan bunga rosela dan terapi reframing menunjukkan persentase memuaskan (93\%) dan kurang memuaskan (7\%). Pernyataan yang ditulis pada kuesioner meliputi pemahaman terkait dengan materi yang disa mpaikan, respon peserta, kesesuaian materi dengan kebutuhan peserta, keterkaitan antara materi dengan aplikasi yang dapat diterapkan peserta, teknik penyajian, kecukupan waktu, kejelasan materi, minat peserta terhadap materi, serta kepuasan terhadap kegiatan. Berdasarkan hasil rekapitulasi kuesioner diketahui bahwa peserta merasa kurang puas dengan waktu pelaksanaan kegiatan. Mereka menginginkan waktu kegiatan yang lebih lama dari yang telah dilaksanakan. Gambar 4 berikut ini menampilkan persentase kepuasan mitra/peserta terhadap pelaksanaan kegiatan.

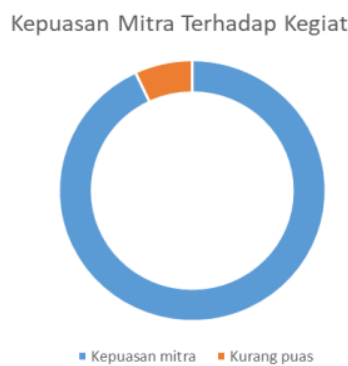

Gambar 4 Tingkat kepuasan peserta

Persentase tingkat kepuasan sebesar 93\% tersebut juga didukung hasil rekapitulasi permintaan keberla njutan kegiatan oleh peserta dengan persentase permintaan tema untuk kegiatan selanjutnya tercantum pada Gambar 5. Hasil rekapitulasi data permintaan keberlanjutan kegiatan yang dikaitkan dengan tema (Gambar 5) menunjukkan bahwa diabetes melitus merupakan tema dengan persentase tertinggi, yaitu $60 \%$. Tema la in yang menarik untuk ditindaklanjuti a dalah perihal kolesterol (20\%) dan a sam urat (19\%). Berdasarkan data tersebut, kegiatan serupa yang akan dilaksanakan pada periode selanjutnya adalah yang berka itan dengan diabetes melitus. Sela in jantung dan stroke, diabetes melitus biasanya juga menjadi salah satu komplikasi dari hipertensi.

\section{Keberlanjutan Kegiatan}

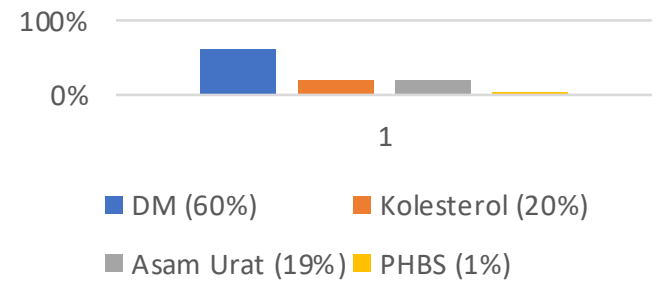

Gambar 5 Hasil rekapitulasi permintaan keberlanjutan kegiatan

Keunggulan kegiatan ini a dalah pelaksanaan yang langsung pada sasaran dengan edukasi penanganan yang rela tif mudah dilakukan oleh lansia, ya itu dengan menyeduh kelopak kering bunga rosela dan melakukan reframing mandiri. Media bantu da lam pelaksanaan kegiatan dapat berupa poster dalam ukuran besar atau a la t peraga. Selain itu, penggunaan bahasa juga menjadi sa lah satu faktor keberhasilan kegiatan. Lansia lebih mudah memahami ma teri yang disampaikan dengan komunikasi verbal dan nonverbal serta menggunakan bahasa awam atau bahasa daerah setempat. Terkait dengan pemahaman materi, diperlukan pengulangan sebagai upaya crosscheck mengenai keterserapan informasi yang diberikan dan membantu lansia untuk mengingat hal-hal penting dalam kegiatan sehingga a kan mudah dilakukan a pabila diperlukan.

Penanganan hipertensi pada kegiatan ini dilakukan secara menyeluruh, baik dari segi fisik maupun psikis. Penanganan dari segi fisik dilakukan dengan penyuluhan dan edukasi perihal hipertensi, baik definisi, gejala, cara pengecekan, faktor risiko, maupun komplikasi dan penanganannya. Penanganan dari segi psikis dilakukan dengan terapi reframing, yaitu terapi mengolah pikiran negatif menjadi pikiran positif dengan membingkai ulang sudut permasalahan sehingga penderita lebih mampu mensyukuri keadaan. Dengan bersyukur, perasaan akan terasa lebih nyaman sehingga saraf yang menegang akibat stres dapat mengendur dan tekanan darah menjadi lebih lancar serta menurun. Dalam kegiatan ini juga dilakukan penyerahan sejumlah bibit tanaman rosela kepada mitra kegiatan. Bibit tanaman tersebut diharapkan dapat dibudidayakan, dikembangkan, dijaga kelangsungan hidupnya, dan dimanfaatkan untuk hal-hal yang bermanfaat bagi desa, termasuk meningkatkan taraf kesehatan masyarakat di Desa Klumprit, Mojolaban, Sukoharjo.

\section{KESIMPULAN}

Berdasarkan analisis data kuesioner pre-test dan post-test diketahui bahwa terdapat peningkatan ratarata pengetahuan peserta mengenai hipertensi dan penanganannya, yaitu dari 54,74 menjadi 84,71. Adapun hasil analisis data menggunakan paired sample 
t-test menunjukkan perbedaan yang signifikan antara sebelum dan setelah diberikan perlakuan.

Sela in itu, persentase tingkat kepuasan peserta pada kegiatan ini mencapai $93 \%$ yang berarti memuaskan. Persentase permintaan peserta untuk keberlanjutan kegiatan ini pada periode berkutnya mencapai $60 \%$ dengan tema yang diinginkan perihal dia betes melitus. Tema-tema la in yang diinginkan oleh peserta a dalah tema perihal kolesterol (20\%), tema perihal asam urat (19\%), dan sebanyak 1\% mengusulkan tema yang berkaitan dengan perilaku hidup bersih dan sehat.

Kesa daran lansia penderita hipertensi yang masih renda huntuk rajin melakukan medical check-up adalah salah satu permasalahan yang dihadapi masyarakat Desa Klumprit. Permasalahan tersebut disebabkan oleh pengetahuan lansia yang masih rendah perihal bahaya dan komplikasi penyakit hipertensi. Sela ma ini, solusi yang dilakukan, yaitu penyediaan layanan kesehatan (posyandu lansia) belum cukup untuk menyelesaikan permasalahan yang dihadapi. Oleh karena itu, kegiatan ini diharapkan dapat membantu dan memotivasi para lansia penderita hipertensi agar dapat melakukan penanganan mandiri dan bekerja sa ma dengan mitra. Penanganan mandiri ya ng tetap dipantau secara berkala dan edukasi berkelanjutan yang difasilitasi kader posyandu la nsia diharapkan dapat meningkatkan angka kesehatan penderita hipertensi di Desa Klumprit, Kecamatan Mojolaban, Kabupaten Sukoharjo.

\section{UCAPAN TERIMA KASIH}

Ucapan terima kasih para penulis sampaikan kepada LPPM STIKES Na sional a tas pemberian perijinan dan dana internal untuk kegiatan pengabdian kepada masyarakat, selain itu juga kepada perangkat desa, ka der posyandu sekaligus peserta posyandu lansia yang menjadi peserta dalam kegiatan pengabdian kepada masyarakat.

\section{DAFTAR PUSTAKA}

Arianto. (2013). Komunikasi Kesehatan. Jurnal Ilmu Komunikasi, 3(2), 1-13.

Kementerian Kesehatan Republik Indonesia. (2013). Riset Kesehatan Dasar. Badan Penelitian dan Pengembangan Kesehatan, Kementerian Keseha tan Republik Indonesia.

Mardiah, S.H.,Arifa h, R., Reki, W. (2009). Budi Daya Pengolahan Rosela Si Merah Segudang Manfaat. PT Agro Media Pustaka, Ja karta

Maryani, H., Kristiana, L.(2008). Khasiat dan Manfaat Rosela. Agromedia Pustaka: Jakarta.

Notoatmodjo, S. (2003). Pendidikan dan Perilaku Kesehatan. Jakarta: Rineka Cipta.

Purnomo, H. (2009). Pencegahan dan Pengobatan Penyakit yang Paling Mematikan. Jakarta: Buana Pustaka.

Rostinawati, T. (2009). Aktivitas Antibakteri Ekstrak Etanol Bunga Rosella (Hibiscus Sabdariffa L.) Terha dap Escherichia coli,Salmonella typhi dan Staphylococcus aureus dengan Metode Difusi Agar. Skripsi. Fakultas Farmasi, Universitas Padjajaran: Bandung.

Tanjong, A. (2011). Pengaruh Konsentrasi Ekstrak KelopakBunga Rosella (Hibiscus Sabdariffa L.) Terhadap Koloni Candida Albicans Yang Terda pat Pa da PlatGigi Tiruan. Skripsi. Fakultas Kedokteran Gigi, Universitas Hasanuddin: Makassar

Widyanto, P., Nelistya, A. (2009). Rosella Aneka Olahan, Khasiat dan Ramuan. Penebar Swa daya: Depok.

World Health Orga nization. (2002). Reducing Risks, Promoting Healthy Life [World Health Report 2002]. WHO, Geneva, Switzerland. 
